\title{
Maternal and neonatal outcome in premature rupture of membranes: a retrospective study
}

\author{
Shery Angel Rajakumar, Sindhura Myneni*, Ajay Nickson Samuel
}

Department of Obstetrics and Gynecology, Chettinad Hospital and Research Institute, Chennai, Tamil Nadu, India

Received: 04 January 2021

Accepted: 06 February 2021

*Correspondence:

Dr. Sindhura Myneni,

E-mail: sindhuramyneni15@gmail.com

Copyright: (C) the author(s), publisher and licensee Medip Academy. This is an open-access article distributed under the terms of the Creative Commons Attribution Non-Commercial License, which permits unrestricted non-commercial use, distribution, and reproduction in any medium, provided the original work is properly cited.

\begin{abstract}
Background: Premature rupture of membranes (PROM) is one of the most challenging and controversial obstetric dilemma which occur even in low risk pregnancies. This study was done to analyse the maternal and neonatal outcomes in PROM cases.

Methods: This was a retrospective study conducted in the department of Obstetrics and Gynaecology at Chettinad Hospital and Research Institute, during a period of 3 years from August 2017 to August 2020. All the women who admitted with PROM were included in the study. The data regarding parity, gestational age, number of fetuses, presentation, duration of PROM, PROM to delivery interval, mode of delivery, weight of the baby, NICU admission was collected from the hospital records and analysed.

Results: A total of 115 cases of PROM were recorded. High incidence is found in the age group of 20-30 years. Among them $73.04 \%$ were admitted at term. $71.3 \%$ were primigravida. $58.26 \%$ of them delivered vaginally where as $41.74 \%$ delivered by LSCS. Majority of them admitted within 6 hours of PROM. Majority of them delivered within 12 hours of PROM. High APGAR scores in majority of the cases. Most of the babies had birth weight $>2.5 \mathrm{~kg} .16$ babies were admitted in NICU. There was no maternal mortality in our study though we had one neonatal mortality.

Conclusions: Careful identification of present or impending complications and individualizing the management based on gestational age and presence of complications holds good in optimising fetomaternal outcome in PROM.
\end{abstract}

Keywords: APGAR, LSCS, Morbidity, Mortality, NICU, PROM

\section{INTRODUCTION}

Premature rupture of membranes (PROM) is defined as spontaneous rupture of membranes at any time beyond 28 weeks but before the onset of labour. ${ }^{1}$ PROM occurs in 5$10 \%$ of all pregnancies, of which $80 \%$ occurs at term. ${ }^{2}$ PROM is the cause of about one third of all preterm births. ${ }^{3}$ PROM results in significant maternal and fetal morbidity and mortality. ${ }^{4,5}$ Maternal complications include intra-amniotic infection, placental abruption (2$9 \%$ ) and post-partum endometritis (15-25\%). Uncommon but serious complications of PROM which are conservatively managed include retained placenta and haemorrhage requiring $\mathrm{D} \& \mathrm{C}(12 \%)$, maternal sepsis $(0.8 \%)$ and $0.14 \%$ maternal death. ${ }^{3,6}$ PROM is associated with $18-20 \%$ of perinatal mortality and $21.4 \%$ morbidity. ${ }^{7,8}$ Sepsis, asphyxia and pulmonary hyperplasia are the three main causes of fetal death associated with PROM. ${ }^{9}$

Spontaneous labour follows term PROM at 24, 48 and 96 hours in $70 \%, 85 \%$ and $95 \%$ of women respectively. ${ }^{10,11}$ Evidence shows that induction of labour as opposed to expectant management, decreases the risk of chorioamnionitis without increasing cesarean section rate. ${ }^{12-14}$ Many trials have concluded that planned early birth leads to reduced maternal infections, reduced neonatal intensive and special care admissions and greater maternal satisfaction. As prevention of PROM is difficult due to its multifactorial etiology, it is important to concentrate more on management of PROM to reduce its complications. 
Maternal and fetal outcome in PROM is very important to reduce maternal and fetal mortality and for better management and prevention of complications. Hence, this study was carried out to analyse maternal and fetal outcomes in PROM.

\section{METHODS}

This was a retrospective study conducted in the department of Obstetrics and Gynecology at Chettinad Hospital and Research Institute, which is a tertiary care teaching hospital. All the women who were admitted with PROM during a period of 3 years from August 2017 to August 2020 were included in the study. The data regarding parity, Gestational age, number of fetuses, presentation, duration of PROM, PROM to delivery interval, mode of delivery, weight of the baby and NICU admissions was collected from the hospital records, and entered in Microsoft excel spread sheet and analysed by using SPSS software.

\section{RESULTS}

A total of 115 cases of PROM were recorded from August 2017 to august 2020. Table 1 shows the distribution of patients admitted with PROM in which high incidence is found in the age group of 20-30 years. Among them $73.04 \%$ were admitted at term and $26.96 \%$ patients came before 37 completed weeks of gestation (Figure 1).

Table 1: Showing age wise distribution of PROM cases.

\begin{tabular}{|lll|}
\hline Age & No. of patients & Percentage \\
\hline $\mathbf{2 0}$ & 3 & 2.61 \\
\hline $\mathbf{2 0 - 2 5}$ & 51 & 44.35 \\
\hline $\mathbf{2 6 - 3 0}$ & 45 & 39.13 \\
\hline$>\mathbf{3 0}$ & 16 & 13.91 \\
\hline
\end{tabular}

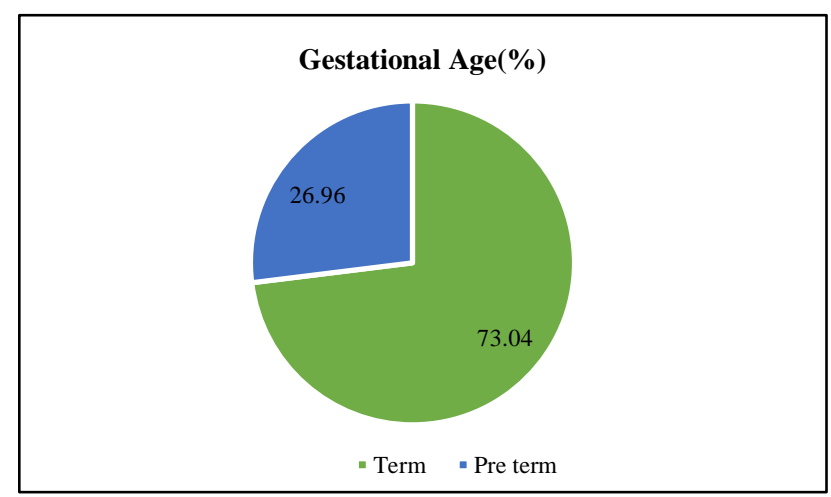

Figure 1: Showing distribution of patients according to gestational age.

In our study $71.3 \%$ were primigravida while $28.70 \%$ were multigravida (Figure 2). $58.26 \%$ of them delivered vaginally where as $41.74 \%$ delivered by LSCS (Figure 3).
Fetal distress, failed induction, meconium stained liquor, Previous LSCS were the most common indications of LSCS. We had only one cord prolapse in our current study.

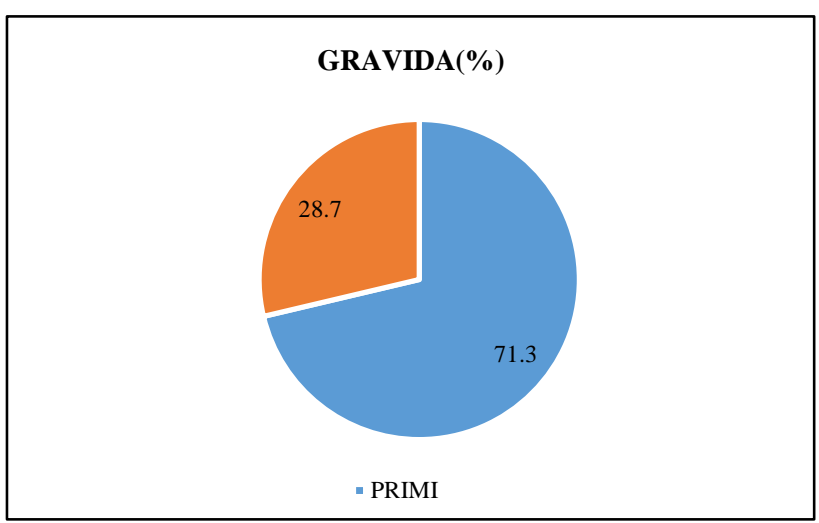

Figure 2: Showing distribution of patients according to gravida.

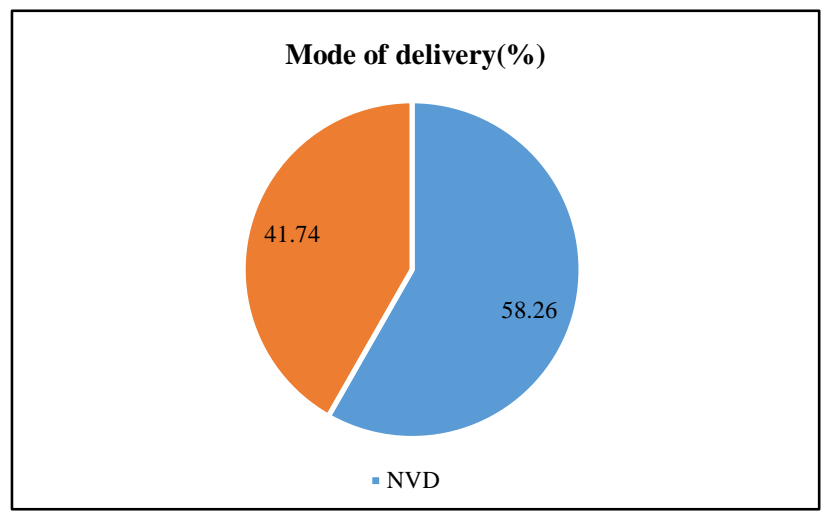

Figure 3: Showing distribution of patients according to mode of delivery.

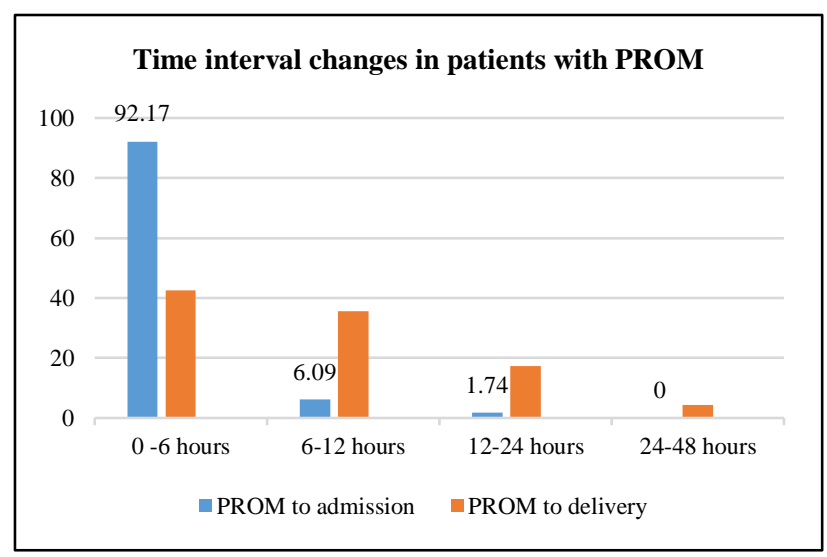

Figure 4: Showing Time interval changes admitted with PROM.

Figure 4 shows the time interval related changes in cases admitted with PROM. Majority of them admitted within 6 hours of PROM. Majority of them delivered within 12 hours of PROM. Only $4.35 \%$ delivered within $24-48$ 
hours. In our present study we observed high APGAR scores in majority of the cases, only 10 babies had APGAR score of $<7$. Most of the babies had birth weight $>2.5 \mathrm{~kg}$, only 35 babies were $<2.5 \mathrm{~kg}$. 16 babies were admitted in NICU in view of meconium stained liquor, fetal distress, preterm, low birth weight and IUGR (Table 2). There was no maternal mortality in our study though we had one neonatal mortality in view of extreme preterm cord prolapse.

Table 2: Showing number of babies admitted in NICU.

\begin{tabular}{|ll|}
\hline NICU admission & No. of babies (\%) \\
\hline Yes & $16(13.91)$ \\
\hline No & $99(86.09)$ \\
\hline
\end{tabular}

\section{DISCUSSION}

Premature rupture of membranes (PROM) is a common complication of pregnancy leading to increased maternal complications, operative deliveries, neonatal morbidity and mortality. In developing countries like India, the incidence of maternal and neonatal morbidities are high, especially in a low resource setting. Early diagnosis and careful management helps in reducing maternal and neonatal morbidities.

In our present study, high incidence of PROM is in the age group of 20-30 years which is similar to other studies. ${ }^{15,16}$ Though there are many studies on relevance of PROM to age of the patients, many researches have also come out which showed no relationship to age and PROM. Majority of the PROM patients were primi in the current study which is in comparison with various studies. ${ }^{17-19}$ Majority $(73.09 \%)$ of them had term PROM in our present study which coincides with the other studies who revealed similar type of findings in relation to gestational age. ${ }^{20,21}$ Rate of normal vaginal delivery was $58.26 \%$ and cesarean section was $41.74 \%$ in our study. Rate of LSCS ranged from $8.3 \%$ to $56 \%$ whereas rate of spontaneous vaginal delivery was $42.3 \%$ to $88 \%$ which was observed in previous studies. ${ }^{22-24}$ Fetal distress, failed induction, meconium stained liquor, previous LSCS were the most common indications of LSCS similar to other studies. ${ }^{17-19}$ Previous studies reported overall incidence rate of cord prolapse in 0.3$0.5 \%$ of cases and $2-4 \%$ of PROM cases. ${ }^{25-27} \mathrm{We}$ had only one cord prolapse in our study, though the results are not statistically significant, higher number of case studies are needed to conclude the association of cord prolapse with PROM. Majority of them admitted within 6 hours of PROM. Majority of them delivered within 12 hours of PROM, which is in comparison with other studies. ${ }^{17-19}$ Only $4.35 \%$ delivered within $24-48$ hours. In our present study high APGAR scores were observed in the majority of cases. Only 10 babies had APGAR score of $<7$. Most of the babies had birth weight $>2.5 \mathrm{~kg}$, only 35 babies were $<2.5 \mathrm{~kg}$. Only 16 babies were admitted in NICU in view of meconium-stained liquor, fetal distress, preterm, low birth weight and IUGR. There was no maternal mortality in our study though we had one neonatal mortality in view of extreme preterm cord prolapse.

\section{CONCLUSION}

Careful identification of present or impending complications and individualizing the management based on gestational age and presence of complications holds good in optimising fetomaternal outcome in PROM. Intervention with steroids, antibiotics in labour and delivery within 24 hours of PROM will greatly reduce maternal complications and enhances favourable neonatal outcomes.

Funding: No funding sources

Conflict of interest: None declared

Ethical approval: The study was approved by the Institutional Ethics Committee

\section{REFERENCES}

1. Arias F, Bhide AG, Arulkumaran S, Damania K, Daftary SN, eds. Arias' Practical Guide to High Risk Pregnancy and Delivery. 3rd edn. Elsevier Health Sciences; 2012:240-260.

2. Duff P. Premature rupture of membranes in term patients: induction of labor versus expectant management. Clin Obstet Gynecol. 1998;41:883-91.

3. Gibbs RS, Karlan BY, Haney AF, Nygaard IE. Danforth's obstetrics and gynecology. 10th edn. Philadelphia, PA: Lippincott Williams and Wilkins; 2008.

4. ACOG Committee on Practice Bulletins-Obstetrics. ACOG Practice Bulletin No. 80: premature rupture of membranes. Clinical management guidelines for obstetrician-gynecologists. Obstet Gynecol. 2007;109:1007-19.

5. El-Messidi A, Cameron A. Diagnosis of premature rupture of membranes: inspiration from the past and insights for the future. J Obstet Gynaecol Can. 2010;32:561-9.

6. Gabbe SG, Niebyl JR, Simpson JL, Landon MB, Galan HL, Jauniaux ER, et al. Obstetrics: normal and problem pregnancies. 7 th edn. Elsevier Health Sciences; 2016.

7. Liu J, Feng $\mathrm{ZC}, \mathrm{Wu}$ J. The incidence rate of premature rupture of membranes and its influence on fetal-neonatal health: a report from mainland China. J Trop Pediatr. 2010;56:36-42.

8. Wu J, Liu J, Feng Z, Huang J, Wu G. Influence of premature rupture of membranes on neonatal health. Zhonghua Er Ke Za Zhi Chin J Pediatr. 2009;47:4526.

9. Veleminsky M, Sak P. Management of pregnancy with premature rupture of membranes (PROM). J Health Sci Manag Public Health 2006;192-7.

10. Keirse MJ, Ottervanger HP, Smit W. Controversies: prelabor rupture of the membranes at term: the case 
for expectant management. J Perinat Med. 1996;24(6):563-72.

11. Hannah ME, Hodnett ED, Willan A, Foster GA, Di Cecco R, Helewa M, et al. Prelabor rupture of the membranes at term: expectant management at home or in hospital? Obstet Gynecol. 2000;96(4):533-8.

12. Yalınkaya A. Continuous amnioin fusion via an epidural catheter following spontaneous membrane rupture: J Turkish-German Gynecol Assoc. 2013;14:238-41.

13. Akyol D, Mungan T, Unsal A, Yuksel K. Prelabour rupture of the membranes at term no advantage of delaying induction for 24 hours. A N Z J Obstet Gynecol. 1999;39(3):291-5.

14. Shah B, Nagar N, Nagar S. A comparative study of labour induction with intravaginal misoprostol versus intravenous oxytocin in premature rupture of membranes beyond 36 weeks gestation. Int $\mathrm{J}$ Med Sci Public Health. 2013;2(3):632-5.

15. Devi A, Rani R. Premature rupture of membranes- a clinical study. J Obstet Gynecol India. 1996;46:63.

16. Kodkany BS, Telang MA. Premature rupture of membranes. A study of 100 cases. J Obstet Gynaecol. India. 1991;41(4):492-6.

17. Gandhi M, Shah F, Panchal C. Obstetric outcomes in premature rupture of the membrane (PROM). Internet J Gynecol Obstet. 2012;16(2):1-5.

18. Patil S, Patil V. Maternal and foetal outcome in premature rupture of membranes. IOSR-J Dent Med Sci. 2014;13(12):56-8310.

19. Gahwagi MM, Busarira MO, Atia M. Premature rupture of membranes characteristics, determinants, and outcomes of in Benghazi, Libya. Open J Obstet Gynecol. 2015;5(09):494.
20. Adeniji AO, Atanda OO. Interventions and neonatal outcomes in patients with premature rupture of fetal membranes at and beyond 34 weeks gestational age at a tertiary health facility in Nigeria. J Adv Med Med Res. 2013:1388-97.

21. Biswas T, Das SK, Kundu S. Preterm prelabour rupture of membranes at 34-37weeks' gestation: intentional delivery versus expectant management JMSCR.2014;2(6):1348-57.

22. Bangal VB. Induction of labour versus expectant management for premature rupture of membranes at term. Int J Biomed Res. 2012;3(3):164-70.

23. Malik HZ, Khawaja NP, Zahid B, Rehman R. Sublingual versus oral misoprostol for induction of labour in prelabour rupture of membranes at term. $\mathrm{J}$ Coll Phys Surg Pak. 2010;20(4):242-5.

24. Kappy AK. Premature rupture of membranes: a conservative approach. Am J Obstet Gynecol. 1979;134 (6):655-61.

25. Sacks M, Baker TH. Spontaneous premature rupture of the membranes. A prospective study. Am J Obstet Gynecol. 1967;97(7):888-93.

26. Russell KP, Anderson GV. The aggressive management of ruptured membranes. Am J Obstet Gynecol. 1962;83(7):930-7.

27. Gunn GC, Mishell DR Jr, Morton DG. Premature rupture of the fetal membranes. A review. Am J Obstet Gynecol. 1970;106(3):469-83.

Cite this article as: Rajakumar SA, Myneni S, Samuel AN. Maternal and neonatal outcome in premature rupture of membranes: a retrospective study. Int J Reprod Contracept Obstet Gynecol 2021;10:1046-9. 